\title{
Stabilization training versus equilibrium training in karate athletes with deafness
}

\author{
Bihter Akınoğlu,**, Tuğba Kocahan ${ }^{2}$ \\ 'Department of Physiotherapy and Rehabilitation, Faculty of Health Sciences, Ankara Yıldırım Beyazıt University, Ankara, Turkey \\ ${ }^{2}$ Center of Athlete Training and Health Research, Department of Health Services, Sports General Directorship, The Ministry of Youth and Sports, Ankara, Turkey
}

The aim of this study is to compare the effect of stabilization and equilibrium training on hip muscle strength and balance performance of karate athletes with deafness. Twenty-seven athletes from the National Deaf Karate Team (18 males, nine females) with an average age of $24.53 \pm 3.62(18-43)$ years were included in this study. The athletes were randomly assigned to either stabilization or equilibrium training group. Both training programs lasted 6 weeks with once per day and 5 days per week sessions. The assessment of muscle strength and balance performance was done before and after the training. The muscle strength and balance have improved in both training groups $(P<0.05)$, but while there was no difference in the results of muscle strength between the groups $(P>0.05)$, balance performance was better in the equilibrium training group $(P<0.05)$. In conclusion, stabilization and equilibrium training have helped the karate athletes with deafness to improve their muscle strength and balance performance.

Keywords: Deaf, Disability, Hearing, Impairment, Sport, Training

\section{INTRODUCTION}

Balance as defined as the ability to maintain stability before, during and after an intentional movement with postural adjustments and by reacting rapidly and affectively to the external perturbations and other destabilizing conditions (Burton and Davis, 1992; Casselbrant et al., 2000). Individuals with hearing impairment have lesser ability to maintain static balance, to perform dynamic coordination of the body, to move the body extremities independently and to control the speed of the movements as compared to people with normal hearing (Effgen, 1981; Majlesi et al., 2014). Therefore, people with hearing impairment have difficulty in performing daily activities that involve balance (Gheysen et al., 2008).

The central nervous system (CNS) is responsible for postural control, stability and maintaining the balance of the body. The CNS functions along with the somatosensorial, vestibular and visual systems concomitantly for the postural and balance control (Steindl et al., 2006). There are anatomical and physiological ties between the hearing and balancing organs of the body, and hearing impairment impacts the muscular coordination and interaction of the two. This causes a chain reaction, in which the loss of hearing reduces the motor functions by impacting balance, and the decrease in motor functions makes it harder to maintain good posture, postural stabilization and balance (Assaiante et al., 2005).

Sporting activities are recommended for the rehabilitation of individuals with hearing impairment to minimize the negative effects of disability (Effgen, 1981; Majlesi et al., 2014). Sports also help them to increase their muscular strength and balance skills, which leads to the development of psychomotor and physical fitness, and gaining orientation and movement skills needed for daily activities (Korologou et al., 2015; Walowska et al., 2018). Muscular strength and balance are also important factors for success in performing sports. These are particularly paramount in karate sport, in which the combative nature of the sport demands significant balancing skills and muscular strength (Leong et al., 2011; Morán-Navarro et al., 2015; Perrin et al., 2002).

In the studies related to the individuals with hearing impairment,
*Corresponding author: Bihter Akınoğlu (iD https://orcid.org/0000-0002-8214-7895 Department of Physiotherapy and Rehabilitation, Faculty of Health Sciences, Ankara Yildırım Beyazıt University, Ankara, Turkey

E-mail: rgkardelen@yahoo.com

Received: June 10, 2019 / Accepted: July 20, 2019
This is an Open Access article distributed under the terms of the Creative Commons Attribution Non-Commercial License (http://creativecommons.org/licenses/by-nc/4.0/) which permits unrestricted non-commercial use, distribution, and reproduction in any medium, provided the original work is properly cited. 
we see that most of them focus on the measurement and comparison of the physical characteristics between the hearing impaired and healthy individuals (Atasavun Uysal et al., 2010; Kowalewski et al., 2018; Markovic et al., 2015; Patel et al., 2017; Szulc et al., 2017; Walowska et al., 2018; Wolter et al., 2016). As for the studies on athletes with hearing impairment, the comparisons were generally with the deaf individuals having a sedentary lifestyle. However, there were no studies available on deaf athletes related to the effect of sports training on balance and muscular strength.

In our study, we hypothesize that athletes with hearing impairment that are likely to have balance and muscular strength deficiencies can improve with the help of stabilization and equilibrium trainings. Therefore, our study focuses on investigating the effect of isokinetic stabilization and equilibrium trainings on the hip flexor and extensor muscular strength and balance performance of karate athletes.

\section{MATERIALS AND METHODS}

\section{Participants and procedures}

Thirty-two athletes ( $\mathrm{n}=32$ ) from Ankara (Turkey) Athlete Research and Education Center, who were also members of the National Deaf Karate Team, were recruited for this study. The selection criteria of the athletes were; being older than 18 years old, having a medically diagnosed hearing impairment condition (a hearing level of in both ears $>55 \mathrm{~dB}$ without cochlear implantation), ability to understand simple instructions, being a member of the 2017 National Deaflympics team, being a karate athlete for at least three years and volunteering to participate in this study. The elimination criteria included: gaining or losing weight enough to alter body mass index (BMI) during the treatment; suffering cervical and/or lumbar disc herniation; having any kind of orthopedic problems, having a recent acute injury causing cognitive, physical or visual impairments; and having any neurological, orthopedic or cardiovascular diseases. Twenty-seven athletes were included as they met these criteria.

The study consisted of a two-stage randomized trial lasting 6 weeks. Baseline measurements were taken from all the athletes after receiving a signed consent both from the athletes as well as their coaches covering the detailed nature of the study. A translator was present to help with communication. Following the baseline assessment, the athletes were randomly assigned to either a stabilization training group or an equilibrium training group using a computer-generated table of random numbers in presealed envelopes. This study was based on volunteerism and designed ac- cording to the Declaration of Helsinki. Ethics Committee approval for this study was obtained from a University Ethical Committee $(08 / 06 / 2017 ; 32 ; 596)$.

\section{Study structure}

All athletes were enrolled in one of the two training programs mentioned below (stabilization training by Isomed 2000 isokinetic device [D\&R Ferstl GmbH, Hemau, Germany] or equilibrium training by Human Body Equilibrium 360 device [HUBER 360, LPG Systems, France]). During the first and last visits, athletes underwent a complete medical evaluation that included measurements of height, weight, hip muscle strength, and balance evaluation. After the first visit, they were randomly assigned to the stabilization or equilibrium groups. The study was performed with 13 athletes in the isokinetic stabilization training group (nine males and four females) (three males kata, others kumite) and 14 athletes in the equilibrium training group (nine males and five females) (three males kata, others kumite). The exercise schedule was $30 \mathrm{~min} /$ day and 5 days/wk for both groups. Each training session started with a warm-up phase that included 3-min mobility/ calisthenics exercises. Each session was monitored by a physiotherapist and was supervised by a sport physician. In addition to the training protocol, all athletes continued to participate in their own team workouts conducted by their team coaches that involve $2-3 \mathrm{hr} /$ day and 5 days/wk sessions.

\section{Training sessions}

\section{Isokinetic stabilization training program}

The isokinetic stabilization training program was developed and administered as a one-on-one session conducted by an experienced physiotherapist for 6 weeks using an isokinetic device. This training program is based on the existing literature and is offered to enhance motor skills and balance (Eliöz et al., 2013; EngelYeger and Weissman, 2009; Gheysen et al., 2008; Hartman et al., 2007; Leong et al., 2011; Morán-Navarro et al., 2015; Perrin et al., 2002). The effectiveness of the program was tested on two deaf athletes prior to the intervention period. Each training session started with a warm-up session that included 3-min mobility/calisthenics exercises. For this training, the athlete was asked to stand in front of the isokinetic device with arms attached to the body and elbows flexed $90^{\circ}$. The isokinetic device was positioned for the athlete's posture. During the stabilization exercises, feedback was given to the athlete with the help of the instructions from the device's monitor to make sure that she/he remained inside the border drawn on the floor with his feet and his lower ex- 
tremities constant. The intensity of effort was carefully monitored during each training session using the maximum stability force by pushing the handle of the IsoMed 2000 device right or left. We have then introduced stabilization via $60 \%$ sec angular velocity lateralization of the movable handle. Throughout the entire exercise program, particular attention was given on keeping a neutral posture and stable core during the stabilization exercises. Stabilization exercise session was total 30 min that was comprised of 10 repetitions of three sets of 1-min exercise. Thirty-second breaks were taken between each repetition.

\section{Equilibrium training program}

The equilibrium training was performed on the Human Body Equilibrium 360 device under direct supervision of a trained physiotherapist. Each training session started with a warm-up session that included 3-min mobility/calisthenics exercises. This warm-up session was followed by a combined core and balance exercise on the computer-controlled Huber device for $30 \mathrm{~min}$. This training program had total three sets, each of which consists of 10 min of training and 5 min of rest. The program particularly included push and pull exercises on the handles of the device with different postures (feet parallel, feet apart at waist width, right or left forward lunge), with different hand positions (chest level, shoulder level, waist level), and towards different directions (forward/ backward, upward/downward, and left/right). The intensity of effort was carefully monitored during each training session using special 3-axial force sensors embedded in the handles of the Huber device. We introduced balance perturbations via low-velocity rotation of the movable platform. Throughout the exercise program, both core and balance perturbations were included in each session. Particular attention was given to keep a neutral posture and stable core during all exercises (Markovic et al., 2015).

\section{Measurements}

Measurements were recorded twice by the same physiotherapist who is blinded to the randomization the day after admission (pre) and the day after training finish (post) at the same time of the days.

\section{Anthropometric variables}

The athletes' body weight was measured by digital a scale and their height were measured by stadiometer (SECA-Mod.220, Seca GmbH \& Co. KG., Hamburg, Germany). The formula used for calculating the BMI is taking weight in kilograms $(\mathrm{kg})$ divided by height in meters $(\mathrm{m})$ squared.

\section{Hip flexor and extensor muscle strength assessment}

Isokinetic muscle strength was assessed by the IsoMed 2000 isokinetic device. Before starting the test, the athletes were asked to run in low-intensity for $10 \mathrm{~min}$ as a warm-up exercise. After the warm-up, the athletes were taken individually into the isokinetic device, and the device was adjusted according to the individual's anthropometric structure.

Hip flexor/extensor muscle strength was assessed in the supine position at $10^{\circ}-100^{\circ}$ flexion (the definitions and protocols in the IsoMed 2000 user's manual were followed). Before the isokinetic strength test, five repetitive hip flexion/extension movements were performed sub maximally at an angular velocity of $60 \%$ sec to allow the athlete to warm-up and to become familiar with the movement. After the warm-up, a 1-min rest was taken. In the isokinetic test protocol, five repetitive maximal hip flexion/extension movements were performed at an angular velocity of $60 \% \mathrm{sec}$. After one minute of rest, the test was completed by performing 15 repetitive maximal hip flexion/extension movements at an angular velocity of $240 \% \mathrm{sec}$. The evaluations were performed bilaterally. The dominant side was evaluated first and the nondominant side after $3 \mathrm{~min}$. The hip flexion/extension peak torque value for both extremities and for both angles were recorded (Kocahan and Akınoğlu, 2018).

\section{Balance assessment}

Balance assessment was carried out at the Human Body Lab. As part of a balance test, stability tests were performed on the athletes to measure how long they can hold their position standing up with their eyes open and close during a 50-sec period. During this test, the length and the area that the athlete drew away from the center line were recorded. Single-leg balance tests were also performed, in which similar measurements were taken with the athlete standing up with one leg in knee flexion position and the other on the ground, during a 30-sec period (Akınoğlu and Kocahan, 2018). The length values obtained as a result of these measurements were recorded as $\mathrm{mm}$, and the area values were recorded as $\mathrm{mm}^{2}$ (The evaluation protocol for the HUBER 360 device used in the study is available at http://international.chattgroup. com).

\section{Statistical analysis}

The collected data were evaluated using the Statistical Package for the Social Science 20.0 software for Windows and by a descriptive statistical analysis (frequency, mean, minimum and maximum, and standard deviation). Before starting this study, a power 
analysis was performed to determine the number of athletes required and a sample size of 12 athletes per group was estimated to provide $80 \%$ power at an alpha level of 0.05 . We anticipated a $10 \%$ dropout rate and targeted a starting population of 26 athletes. At the end, the study was initiated with 32 athletes. After the inclusion and exclusion criteria 27 athletes were included in the study. The Kolmogorov-Smirnov test was used to check if the data distribution was normal, and it was determined that the data did not have a normal distribution. We consequently used the Wilcoxon signed-rank test to compare the treatment groups' data before and after the treatment. The Mann-Whitney $U$-test was used to make comparisons between the two groups. The statistical significance level was a $P$-value of less than 0.05 , and we used $95 \%$ confidence intervals.

\section{RESULTS}

Baseline characteristics are presented in Table 1, where we can see that there were no differences between the baseline characteristics of both groups. It was also determined that the athletes did

Table 1. Comparison of demographics variables and sport years of the groups

\begin{tabular}{|c|c|c|c|c|c|c|}
\hline \multirow{2}{*}{ Variable } & \multicolumn{2}{|c|}{ Isokinetic stabilization training group } & \multicolumn{2}{|c|}{ Balance training group } & \multirow{2}{*}{$U$} & \multirow{2}{*}{$P$-value ${ }^{\mathrm{al}}$} \\
\hline & Mean (IQR) & Range & Mean (IOR) & Range & & \\
\hline Age (yr) & $24(21-33)$ & $18-42$ & $24.50(21-29)$ & $18-43$ & 85.50 & 0.789 \\
\hline Height (m) & $170(166-176)$ & 161-184 & $169(166-178)$ & 148-188 & 83.00 & 0.697 \\
\hline Weight (kg) & $69(62-77)$ & 48-91 & $69(59-78)$ & $51-114$ & 84.00 & 0.734 \\
\hline $\mathrm{BMI}\left(\mathrm{kg} / \mathrm{m}^{2}\right)$ & $22.74(20.90-24.72)$ & $18.52-29.71$ & $25.36(21.15-27.58)$ & $18.51-32.25$ & 71.50 & 0.344 \\
\hline Sport years (yr) & $5.75(4-12)$ & $3-20$ & $5(3-11)$ & $3-12$ & 57.50 & 0.255 \\
\hline
\end{tabular}

$I Q R$, interquartile range; $\mathrm{BMI}$, body mass index.

alMann-Whitney U-test.

Table 2. Comparison of pretraining results of balance and isokinetic strength assessment

\begin{tabular}{|c|c|c|c|c|c|c|}
\hline \multirow{2}{*}{ Balance assessment } & \multicolumn{2}{|c|}{ Isokinetic stabilization training group } & \multicolumn{2}{|c|}{ Balance training group } & \multirow{2}{*}{$U$} & \multirow{2}{*}{$P$-value } \\
\hline & Mean (IOR) & Range & Mean (IQR) & Range & & \\
\hline \multicolumn{7}{|l|}{ Eyes opened stability test } \\
\hline Length (mm) & 585.90 (560.69-666.73) & 484.76-1,475.88 & $558.18(493.42-832.46)$ & 397.27-942.28 & 77.00 & 0.497 \\
\hline Area $\left(\mathrm{mm}^{2}\right)$ & $195.12(161.83-376.03)$ & $100.07-1,486.65$ & 220.31 (166.85-518.80) & $66.39-686.73$ & 89.00 & 0.923 \\
\hline \multicolumn{7}{|l|}{ Eyes closed stability test } \\
\hline Length (mm) & 770.93 (665.78-859.47) & $628.56-1,024.75$ & $855.00(718.82-1,198.97)$ & $460.01-1,417.15$ & 68.00 & 0.264 \\
\hline Area $\left(\mathrm{mm}^{2}\right)$ & $414.58(252.63-373.09)$ & $193.73-697.66$ & $354.38(185.67-1,125.40)$ & $111.21-1,566.87$ & 79.00 & 0.560 \\
\hline \multicolumn{7}{|l|}{ DM single-leg test } \\
\hline Length (mm) & $1,658.05(1,466.99-1,953.23)$ & $1,082.77-2,570.17$ & $1,823.63(1,268.01-2,128.74)$ & $933.08-2,250.89$ & 90.00 & 0.961 \\
\hline Area $\left(\mathrm{mm}^{2}\right)$ & $1,003.52$ (758.56-1,874.64) & 437.14-2,603.20 & 1,083.87 (499.17-1,555.49) & $231.36-1,758.11$ & 72.00 & 0.357 \\
\hline \multicolumn{7}{|l|}{ NDM single-leg test } \\
\hline Length (mm) & $1,831.19(1,580.65-2,006.95)$ & $1,313.22-3,383.67$ & $1,762.88(1,231.98-1,942.88)$ & $907.22-2,433.34$ & 73.00 & 0.382 \\
\hline Area $\left(\mathrm{mm}^{2}\right)$ & 1,245.00 (861.66-1,600.19) & $496.55-5,156.95$ & 1,099.62 (768.23-1,494.36) & $384.34-4,721.40$ & 78.00 & 0.528 \\
\hline \multicolumn{7}{|c|}{ Isokinetic strength assessment (PT) (Nm) } \\
\hline Flexion $60^{\circ} / \mathrm{sec} \mathrm{DM}$ & $138.60(100.60-155.10)$ & $68.40-163.30$ & $140.20(87.10-168.90)$ & 54.90-199.60 & 82.50 & 0.680 \\
\hline Flexion $60^{\circ} / \mathrm{sec}$ NDM & 126.60 (84.90-168.60) & 69.90-188.10 & 135.50 (83.80-143.80) & 48.40-188.80 & 84.50 & 0.752 \\
\hline Extension $60^{\circ} / \sec \mathrm{DM}$ & $207.10(159.10-270.60)$ & $128.10-329.40$ & 200.80 (148.30-231.90) & $75.60-325.30$ & 82.50 & 0.680 \\
\hline Extension $60^{\circ} / \mathrm{sec} \mathrm{NDM}$ & $186.10(148.30-266.40)$ & 105.60-315.10 & $198.15(146.40-231.60)$ & $67.60-326.10$ & 85.00 & 0.771 \\
\hline Flexion $180^{\circ} / \mathrm{sec} \mathrm{DM}$ & $114.10(84.10-136.30)$ & $66.70-165.90$ & $113.15(70.50-129.60)$ & 54.90-205.20 & 79.00 & 0.560 \\
\hline Flexion $180^{\circ} / \mathrm{sec}$ NDM & $92.10(72.40-116.80)$ & 44.40-169.30 & $107.85(62.80-134.40)$ & 48.40-200.10 & 85.50 & 0.789 \\
\hline Extension $180^{\circ} / \mathrm{sec} \mathrm{DM}$ & $167.40(138.90-249.90)$ & 103.60-278.80 & $180.00(103.30-234.90)$ & $75.60-272.40$ & 78.00 & 0.528 \\
\hline Extension $180^{\circ} / \mathrm{sec} \mathrm{NDM}$ & $171.00(125.80-242.40)$ & 103.30-321.00 & $168.35(113.10-256.90)$ & $67.60-303.60$ & 91.00 & 1.000 \\
\hline
\end{tabular}

IOR, interquartile range; DM, dominant side; NDM, nondominant side; PT, peak torque.

alMann-Whitney U-test. 
Table 3. Comparison of posttraining results of balance and isokinetic strength assessment

\begin{tabular}{|c|c|c|c|c|c|c|}
\hline \multirow{2}{*}{ Balance assessment } & \multicolumn{2}{|c|}{ Isokinetic stabilization training group } & \multicolumn{2}{|c|}{ Balance training group } & \multirow{2}{*}{$U$} & \multirow{2}{*}{$P$-value ${ }^{a}$} \\
\hline & Mean (IOR) & Range & Mean (IOR) & Range & & \\
\hline \multicolumn{7}{|l|}{ Eyes opened stability test } \\
\hline Length (mm) & 552.59 (520.90-675.89) & $402.40-727.93$ & 523.66 (471.68-566.10) & $377.33-659.14$ & 61.00 & 0.145 \\
\hline Area $\left(\mathrm{mm}^{2}\right)$ & $423.35(203.45-548.25)$ & $111.71-833.98$ & 209.49 (115.46-248.62) & $80.79-444.37$ & 45.00 & 0.026 \\
\hline \multicolumn{7}{|l|}{ Eyes closed stability test } \\
\hline Length (mm) & 814.17 (633.49-914.94) & 514.53-1,147.77 & 661.62 (612.26-851.39) & $525.85-1,292.95$ & 74.00 & 0.409 \\
\hline Area $\left(\mathrm{mm}^{2}\right)$ & 475.82 (402.09-770.88) & 237.63-1,231.55 & 408.06 (325.01-549.20) & $185.21-1,438.90$ & 63.00 & 0.174 \\
\hline \multicolumn{7}{|l|}{ DM single-leg test } \\
\hline Length (mm) & $2.08(0.92-2.58)$ & $0.61-5.69$ & $2.01(1.50-4.05)$ & $0.81-6.80$ & 69.50 & 0.297 \\
\hline Area $\left(\mathrm{mm}^{2}\right)$ & $1,269.39(1,199.73-1,699.69)$ & $957.38-1,879.44$ & $1,280.98(1,102.69-1,604.43)$ & $885.84-2,079.20$ & 81.00 & 0.627 \\
\hline \multicolumn{7}{|l|}{ NDM single-leg test } \\
\hline Length (mm) & 986.40 (787.39-1251.84) & $538.50-2,054.31$ & 798.66 (543.61-1,140.59) & $320.69-1,508.50$ & 66.00 & 0.225 \\
\hline Area $\left(\mathrm{mm}^{2}\right)$ & $1,429.14(1,278.08-1,558.80)$ & $1,041.37-1,927.69$ & $1,213.94(1,054.58-1,364.77)$ & $859.88-1,949.64$ & 51.00 & 0.042 \\
\hline \multicolumn{7}{|c|}{ Isokinetic Strength Assessment (PT) (Nm) } \\
\hline Flexion $60^{\circ} / \sec \mathrm{DM}$ & 133.60 (84.90-155.10) & 71.80-164.80 & 120.25 (89.40-135.90) & $53.40-156.60$ & 75.50 & 0.452 \\
\hline Flexion $60^{\circ} / \sec$ NDM & 132.90 (80.10-142.30) & 64.30-183.60 & $120.20(87.90-129.10)$ & $66.90-158.40$ & 81.50 & 0.645 \\
\hline Extension $60^{\circ} / \mathrm{sec} \mathrm{DM}$ & 246.90 (185.80-290.80) & $105.10-350.80$ & $236.25(167.40-270.60)$ & $137.10-387.90$ & 81.00 & 0.627 \\
\hline Extension $60^{\circ} / \sec \mathrm{NDM}$ & $258.60(188.40-315.10)$ & $94.60-339.60$ & $246.35(204.60-309.10)$ & $164.40-363.60$ & 89.00 & 0.923 \\
\hline Flexion $180^{\circ} / \mathrm{sec} \mathrm{DM}$ & $114.90(73.60-116.40)$ & 57.60-154.30 & $104.75(69.00-128.80)$ & 54.90-168.10 & 85.00 & 0.771 \\
\hline Flexion $180^{\circ} / \mathrm{sec}$ NDM & $108.90(74.10-135.40)$ & $55.30-151.90$ & $106.05(71.80-132.60)$ & $60.60-160.60$ & 89.00 & 0.923 \\
\hline Extension $180^{\circ}$ /sec DM & $222.90(162.90-259.60)$ & $110.80-299.10$ & $217.90(159.60-272.80)$ & $96.10-316.30$ & 89.00 & 0.923 \\
\hline Extension $180^{\circ} / \mathrm{sec} \mathrm{NDM}$ & $200.10(173.10-278.10)$ & $92.10-321.00$ & $217.25(173.40-281.40)$ & $119.40-382.30$ & 86.00 & 0.808 \\
\hline
\end{tabular}

IOR, interquartile range; $\mathrm{DM}$, dominant side; NDM, nondominant side; PT, peak torque. alMann-Whitney U-test.

not gain or lose weight enough to alter the BMI. The program attendance was $100 \%$. No issues were observed in either group ( $\mathrm{Ta}-$ ble 1).

The muscle strength and balance performance baseline values are presented in Table 2. Again, there were no differences between the muscle strength and balance performance's baseline values of both groups $(P>0.05)$ (Table 2$)$.

When we compared the posttreatment results between the groups, there were no differences between the hip muscle strength values $(P>0.05)$, but the balance performance of the balance training group was better than those in the stabilization group $(P<0.05)$ (Table 3).

After 6 weeks of training (12 sessions), it was observed that the balance training group show improvements in hip extensor muscle strength $(P<0.05)$, and scored better in the eyes closed stability test area and single-leg tests length of equilibrium performance tests $(P<0.05)$ as compared to before. As for the stabilization training group, the athletes show improvements in hip extensor muscle strength $(P<0.05)$ (Table 4$)$ and scored better in the single-leg tests length of equilibrium performance tests $(P<0.05)$ (Table 5).

\section{DISCUSSION}

In our study that we have investigated how isokinetic stabilization and equilibrium trainings affect the hip flexor and extensor muscles and balance in Deaf Karate Athletes, we have concluded that both types of trainings improved the muscle strength and balance performance, however, equilibrium training was more affective on increasing balance performance.

We have also identified that both types of trainings were affective in increasing the hip extensor muscle strength, but not the hip flexor muscles. Hip muscles along with core muscles play an important role in postural stabilization (Hodges and Richardson, 1997). Besides, hip extensor muscle strength is important for maintaining balance and postural stabilization (Nadler et al., 2002). We conclude from our study that the increase in athletes' balance performance and hip extensor muscle strength is directly related to the relationship between postural stability and hip extensor muscle strength (Hodges and Richardson, 1997; Nadler et al., 2002; Palmer et al., 2017).

Research on deaf athletes and individuals with sedentary life- 
Table 4. Comparison of pre- and posttraining results of balance and isokinetic strength assessment of the stabilization training group

\begin{tabular}{|c|c|c|c|c|c|c|}
\hline \multirow{2}{*}{ Balance assessment } & \multicolumn{2}{|c|}{ Before training } & \multicolumn{2}{|c|}{ After training } & \multirow{2}{*}{$\chi^{2}$} & \multirow{2}{*}{$P$-value ${ }^{\mathrm{a})}$} \\
\hline & Mean (IQR) & Range & Mean (IQR) & Range & & \\
\hline \multicolumn{7}{|l|}{ Eyes opened stability test } \\
\hline Length (mm) & 585.90 (560.69-666.73) & $484.76-1,475.88$ & 552.59 (520.90-675.89) & $402.40-727.93$ & -1.433 & 0.152 \\
\hline Area $\left(\mathrm{mm}^{2}\right)$ & 195.12 (161.83-376.03) & $100.07-1,486.65$ & $423.35(203.45-548.25)$ & $111.71-833.98$ & -0.454 & 0.650 \\
\hline \multicolumn{7}{|l|}{ Eyes closed stability test } \\
\hline Length (mm) & 770.93 (665.78-859.47) & $628.56-1,024.75$ & 814.17 (633.49-914.94) & $514.53-1,147.77$ & -0.804 & 0.422 \\
\hline Area $\left(\mathrm{mm}^{2}\right)$ & 414.58 (252.63-373.09) & 193.73-697.66 & 475.82 (402.09-770.88) & 237.63-1,231.55 & -3.180 & 0.051 \\
\hline \multicolumn{7}{|l|}{ DM single-leg test } \\
\hline Length (mm) & $1,658.05(1,466.99-1,953.23)$ & $1,082.77-2,570.17$ & 1,269.39 (1,199.73-1,699.69) & $957.38-1,879.44$ & -2.760 & $0.006^{* *}$ \\
\hline Area $\left(\mathrm{mm}^{2}\right)$ & $1,003.52(758.56-1,874.64)$ & $437.14-2,603.20$ & 986.40 (787.39-1,251.84) & $538.50-2,054.31$ & -1.083 & 0.279 \\
\hline \multicolumn{7}{|l|}{ NDM single-leg test } \\
\hline Length (mm) & $1,831.19(1,580.65-2,006.95)$ & $1,313.22-3,383.67$ & $1,429.14(1,278.08-1,558.80)$ & $1,041.37-1,927.69$ & -2.830 & $0.005^{* *}$ \\
\hline Area $\left(\mathrm{mm}^{2}\right)$ & $1,245.00(861.66-1,600.19)$ & $496.55-5,156.95$ & 1,007.29 (837.38-1,297.70) & $658.26-1,949.50$ & -0.874 & 0.382 \\
\hline \multicolumn{7}{|c|}{ Isokinetic strength assessment (PT) (Nm) } \\
\hline Flexion $60^{\circ} / \sec \mathrm{DM}$ & $138.60(100.60-155.10)$ & $68.40-163.30$ & $133.60(84.90-155.10)$ & $71.80-164.80$ & -0.559 & 0.576 \\
\hline Flexion $60^{\circ} / \mathrm{sec} \mathrm{NDM}$ & $126.60(84.90-168.60)$ & $69.90-188.10$ & $132.90(80.10-142.30)$ & $64.30-183.60$ & -1.177 & 0.239 \\
\hline Extension $60^{\circ} / \mathrm{sec} \mathrm{DM}$ & $207.10(159.10-270.60)$ & $128.10-329.40$ & $246.90(185.80-290.80)$ & 105.10-350.80 & -2.201 & $0.028^{*}$ \\
\hline Extension $60^{\circ} / \mathrm{sec} \mathrm{NDM}$ & $186.10(148.30-266.40)$ & 105.60-315.10 & $258.60(188.40-315.10)$ & $94.60-339.60$ & -2.691 & $0.007^{* *}$ \\
\hline Flexion $180^{\circ} / \mathrm{sec} \mathrm{DM}$ & $114.10(84.10-136.30)$ & $66.70-165.90$ & $114.90(73.60-116.40)$ & $57.60-154.30$ & -1.049 & 0.294 \\
\hline Flexion $180^{\circ} / \mathrm{sec}$ NDM & $92.10(72.40-116.80)$ & $44.40-169.30$ & $108.90(74.10-135.40)$ & $55.30-151.90$ & -0.594 & 0.552 \\
\hline Extension $180^{\circ} / \mathrm{sec} \mathrm{DM}$ & $167.40(138.90-249.90)$ & 103.60-278.80 & $222.90(162.90-259.60)$ & $110.80-299.10$ & -2.271 & $0.023^{*}$ \\
\hline Extension $180^{\circ} / \mathrm{sec}$ NDM & $171.00(125.80-242.40)$ & 103.30-321.00 & $200.10(173.10-278.10)$ & $92.10-321.00$ & -2.097 & $0.036^{*}$ \\
\hline
\end{tabular}

$\mathrm{IQR}$, interquartile range; $\mathrm{DM}$, dominant side; NDM, nondominant side; $\mathrm{PT}$, peak torque.

${ }^{*} P<0.05$. ${ }^{* *} P<0.01$. ${ }^{\text {al } W i l c o x o n ~ s i g n e d-r a n k ~ t e s t . ~}$

style show that participating in sports activities improves balance skills and, in fact, active participation in sports was required in increasing balance and postural control (Eliöz et al., 2013; Hartman et al., 2011). The following studies on deaf athletes also exist; Effgen (1981) emphasized that a customized equilibrium exercise was affective in improving balance in deaf kids. Heitkamp et al. (2001) organized a 25-min-6-week balance and strength-oriented training program for deaf individuals (Heitkamp et al., 2001). Walowska et al. (2018) coached a plates class for 41 out of 80 selected deaf individuals for 6 weeks, and coached a physical education class for the rest. At the end of this study, plates classes, which focused on balance and strength skills, were affective on improving balance. In a similar study, Rine et al. (2004) stated that a 12 -week customized exercise, which were held 3 days per week on 21 deaf individuals helped to improving balance.

Our study is in line with the literature, and shows that balance skills have improved in both training groups. However, equilibrium training was more effective than the stabilization training in improving balance skills. In our study, muscle strength measurement method and position were quite different even though the aforementioned device for stabilization training was used. On the other hand, equilibrium training and the relevant measurements were performed with the same device and similar methods. Therefore, it is possible to assume that this might be the reason why the equilibrium training was more affective in improving balance skills. Because, the testing accuracy tends to increase when the type of tests are in the same category of the training (Kraemer et al., 2017). So, balance skills improved better in equilibrium training.

It is important to note that the training programs for the deaf individuals have to be different than the routing exercises, and be customized to meet specific goals (Effgen, 1981; Heitkamp et al., 2001; Rine et al., 2004). These training programs should focus on improving strength and balance skills, which are different than those for healthy individuals (Pankanin, 2018; Rine et al., 2004). In the light of the available literature, our training programs in both groups targeted on improving muscular strength and balance skills with a focus on core and postural stabilities. We did not find any studies in which training sessions were held for deaf individuals. In retrospect, our study is the first and only one which investigates the effect of different training programs on 
Table 5. Comparison of pre- and posttraining results of balance and isokinetic strength assessment of the balance training group

\begin{tabular}{|c|c|c|c|c|c|c|}
\hline \multirow{2}{*}{ Balance assessment } & \multicolumn{2}{|c|}{ Before training } & \multicolumn{2}{|c|}{ After training } & \multirow{2}{*}{$U$} & \multirow{2}{*}{$P$-value } \\
\hline & Mean (IQR) & Range & Mean (IOR) & Range & & \\
\hline \multicolumn{7}{|l|}{ Eyes opened stability test } \\
\hline Length (mm) & $558.18(493.42-832.46)$ & $397.27-942.28$ & 523.66 (471.68-566.10) & $377.33-659.14$ & -1.789 & 0.074 \\
\hline Area $\left(\mathrm{mm}^{2}\right)$ & 220.31 (166.85-518.80) & $66.39-686.73$ & 209.49 (115.46-248.62) & $80.79-444.37$ & -1.475 & 0.140 \\
\hline \multicolumn{7}{|l|}{ Eyes closed stability test } \\
\hline Length (mm) & $855.00(718.82-1,198.97)$ & $460.01-1,417.15$ & 661.62 (612.26-851.39) & $525.85-1,292.95$ & -2.103 & $0.035^{*}$ \\
\hline Area $\left(\mathrm{mm}^{2}\right)$ & $354.38(185.67-1,125.40)$ & $111.21-1,566.87$ & 408.06 (325.01-549.20) & $185.21-1,438.90$ & -0.345 & 0.730 \\
\hline \multicolumn{7}{|l|}{ DM single-leg test } \\
\hline Length (mm) & $1,823.63(1,268.01-2,128.74)$ & $933.08-2,250.89$ & $1,280.98(1,102.69-1,604.43)$ & $885.84-2,079.20$ & -3.107 & $0.002^{* *}$ \\
\hline Area $\left(\mathrm{mm}^{2}\right)$ & 1,083.87 (499.17-1,555.49) & $231.36-1,758.11$ & $798.66(543.61-1,140.59)$ & $320.69-1,508.50$ & -1.224 & 0.221 \\
\hline \multicolumn{7}{|l|}{ NDM single-leg test } \\
\hline Length (mm) & $1,762.88(1,231.98-1,942.88)$ & $907.22-2,433.34$ & $1,213.94(1,054.58-1,364.77)$ & 859.88-1,949.64 & -2.731 & $0.006^{* *}$ \\
\hline Area $\left(\mathrm{mm}^{2}\right)$ & 1,099.62 (768.23-1,494.36) & $384.34-4,721.40$ & 664.05 (590.73-802.88) & $367.43-2,371.33$ & -1.664 & 0.096 \\
\hline \multicolumn{7}{|c|}{ Isokinetic strength assessment (PT) (Nm) } \\
\hline Flexion $60^{\circ} / \mathrm{sec} \mathrm{DM}$ & 140.20 (87.10-168.90) & 54.90-199.60 & $120.25(89.40-135.90)$ & 53.40-156.60 & -1.915 & 0.056 \\
\hline Flexion $60^{\circ} / \mathrm{sec}$ NDM & 135.50 (83.80-143.80) & 48.40-188.80 & $120.20(87.90-129.10)$ & $66.90-158.40$ & -1.381 & 0.167 \\
\hline Extension $60^{\circ} / \mathrm{sec} \mathrm{DM}$ & $200.80(148.30-231.90)$ & $75.60-325.30$ & $236.25(167.40-270.60)$ & 137.10-387.90 & -2.291 & $0.022^{*}$ \\
\hline Extension $60^{\circ} / \mathrm{sec} \mathrm{NDM}$ & $198.15(146.40-231.60)$ & $67.60-326.10$ & $246.35(204.60-309.10)$ & $164.40-363.60$ & -2.982 & $0.003^{* *}$ \\
\hline Flexion $180^{\circ} / \mathrm{sec} \mathrm{DM}$ & $113.15(70.50-129.60)$ & $54.90-205.20$ & $104.75(69.00-128.80)$ & $54.90-168.10$ & -0.408 & 0.683 \\
\hline Flexion $180^{\circ} / \mathrm{sec}$ NDM & $107.85(62.80-134.40)$ & $48.40-200.10$ & $106.05(71.80-132.60)$ & $60.60-160.60$ & -0.314 & 0.753 \\
\hline Extension $180^{\circ} / \mathrm{sec} \mathrm{DM}$ & $180.00(103.30-234.90)$ & $75.60-272.40$ & $217.90(159.60-272.80)$ & $96.10-316.30$ & -2.480 & $0.013^{*}$ \\
\hline Extension $180^{\circ} / \mathrm{sec} \mathrm{NDM}$ & $168.35(113.10-256.90)$ & $67.60-303.60$ & $217.25(173.40-281.40)$ & $119.40-382.30$ & -2.417 & $0.016^{*}$ \\
\hline
\end{tabular}

$\mathrm{IOR}$, interquartile range; $\mathrm{DM}$, dominant side; NDM, nondominant side; PT, peak torque.

${ }^{*} P<0.05$. ${ }^{* *} P<0.01$. al Wilcoxon signed-rank test.

muscular strength and balance performance in professional athletes with hearing impairment.

The limitations of our study included not having a control group and not being able to see the long-term results of the training programs. The main conclusion of our study points out that stabilization and equilibrium trainings have equally improved the muscular strength and balance performance of deaf athletes. Neither type of training was dominant over the other.

\section{CONFLICT OF INTEREST}

No potential conflict of interest relevant to this article was reported.

\section{ACKNOWLEDGMENTS}

The authors would like to thank to PT. Taşkın Özkan for his helping in the statistical analyses.

\section{REFERENCES}

Akınoğlu B, Kocahan T. Comparison of muscular strength and balance in athletes with visual impairment and hearing impairment. J Exerc Rehabil 2018;14:765-770.

Assaiante C, Mallau S, Viel S, Jover M, Schmitz C. Development of postural control in healthy children: a functional approach. Neural Plast 2005;12:109-118.

Atasavun Uysal S, Erden Z, Akbayrak T, Demirtürk F. Comparison of balance and gait in visually or hearing impaired children. Percept Mot Skills 2010;111:71-80.

Burton AW, Davis WE. Assessing balance in adapted physical education: fundamental concepts and applications. Adapt Phys Activ Q 1992;9: $14-46$.

Casselbrant ML, Furman JM, Mandel EM, Fall PA, Kurs-Lasky M, Rockette HE. Past history of otitis media and balance in four-year-old children. Laryngoscope 2000;110(5 Pt 1):773-778.

Effgen SK. Effect of an exercise program on the static balance of deaf children. Phys Ther 1981;61:873-877.

Eliöz M, Sitti S, Koç MC, Murt Z, Koç H. A study on static balance perfor- 
mance of healthy and hearing - impaired football players. Eur J Appl Sci 2013;5:25-28.

Engel-Yeger B, Weissman D. A comparison of motor abilities and perceived self-efficacy between children with hearing impairments and normal hearing children. Disabil Rehabil 2009;31:352-358.

Gheysen F, Loots G, Van Waelvelde H. Motor development of deaf children with and without cochlear implants. J Deaf Stud Deaf Educ 2008; 13:215-224.

Hartman E, Houwen S, Visscher C. Motor skill performance and sports participation in deaf elementary school children. Adapt Phys Activ Q 2011;28:132-145.

Hartman E, Visscher C, Houwen S. The effect of age on physical fitness of deaf elementary school children. Pediatr Exerc Sci 2007;19:267-278.

Heitkamp HC, Horstmann T, Mayer F, Weller J, Dickhuth HH. Gain in strength and muscular balance after balance training. Int J Sports Med 2001;22:285-290.

Hodges PW, Richardson CA. Contraction of the abdominal muscles associated with movement of the lower limb. Phys Ther 1997;77:132-142.

Kocahan T, Akınoğlu B. Determination of the relationship between core endurance and isokinetic muscle strength of elite athletes. J Exerc Rehabil 2018;14:413-418.

Korologou S, Barkoukis V, Lazuras L, Tsorbatzoudis H. Application of the transtheoretical model to physical activity in deaf individuals. Adapt Phys Activ Q 2015;32:223-240.

Kowalewski V, Patterson R, Hartos J, Bugnariu N. Hearing loss contributes to balance difficulties in both younger and older adults. J Prev Med (Wilmington) 2018;3. pii: 12. https://doi.org/10.21767/2572-5483.100033.

Kraemer WJ, Ratamess NA, Flanagan SD, Shurley JP, Todd JS, Todd TC. Understanding the science of resistance training: an evolutionary perspective. Sports Med 2017;47:2415-2435.

Leong HT, Fu SN, Ng GY, Tsang WW. Low-level Taekwondo practitioners have better somatosensory organisation in standing balance than sedentary people. Eur J Appl Physiol 2011;111:1787-1793.

Majlesi M, Farahpour N, Azadian E, Amini M. The effect of interventional proprioceptive training on static balance and gait in deaf children. Res Dev Disabil 2014;35:3562-3567.

Markovic G, Sarabon N, Greblo Z, Krizanic V. Effects of feedback-based balance and core resistance training vs. Pilates training on balance and muscle function in older women: a randomized-controlled trial. Arch Gerontol Geriatr 2015;61:117-123.

Morán-Navarro R, Valverde-Conesa A, López-Gullón J. M, De la CruzSánchez E, Pallarés J. G. Can balance skills predict Olympic wrestling performance? J Sport Health Res 2015;7:19-30.

Nadler SF, Malanga GA, Bartoli LA, Feinberg JH, Prybicien M, Deprince M. Hip muscle imbalance and low back pain in athletes: influence of core strengthening. Med Sci Sports Exerc 2002;34:9-16.

Palmer TB, Thiele RM, Thompson BJ. Age-related differences in maximal and rapid torque characteristics of the hip extensors and dynamic postural balance in healthy, young and old females. J Strength Cond Res 2017;31:480-488.

Pankanin ES. The impact of hearing disorders on the body balance. J Edu Health Sport 2018;8:244-249.

Patel H, Malawade M, Butte-Patil S, Khairnar P, Gawade S. Comparison of balance in children with and without hearing impairment. Int J Healthcare Biomed Res 2017;5:19-27.

Perrin P, Deviterne D, Hugel F, Perrot C. Judo, better than dance, develops sensorimotor adaptabilities involved in balance control. Gait Posture 2002;15:187-194.

Rine RM, Braswell J, Fisher D, Joyce K, Kalar K, Shaffer M. Improvement of motor development and postural control following intervention in children with sensorineural hearing loss and vestibular impairment. Int J Pediatr Otorhinolaryngol 2004;68:1141-1148.

Steindl R, Kunz K, Schrott-Fischer A, Scholtz AW. Effect of age and sex on maturation of sensory systems and balance control. Dev Med Child Neurol 2006;48:477-482.

Szulc AM, Buśko K, Sandurska E, Kołodziejczyk M. The biomechanical characteristics of elite deaf and hearing female soccer players: comparative analysis. Acta Bioeng Biomech 2017;19:127-133.

Walowska J, Bolach B, Bolach E. The influence of Pilates exercises on body balance in the standing position of hearing impaired people. Disabil Rehabil 2018;40:3061-3069.

Wolter NE, Cushing SL, Vilchez-Madrigal LD, James AL, Campos J, Papsin BC, Gordon KA. Unilateral hearing loss 1s associated with $1 \mathrm{~m}-$ paired balance in children: a pilot study. Otol Neurotol 2016;37:15891595. 